\title{
Numerical Modeling and Stability Analysis of Surrounding Rock of Yuanjue Cave
}

\author{
Zhigang Meng, ${ }^{1,2,3}$ Fangzheng Fan, ${ }^{1}$ Xuebin Cui ${ }^{D},{ }^{1}$ Shu Tao, ${ }^{1}$ and Yi Cao ${ }^{1}$ \\ ${ }^{1}$ State Key Laboratory for Geomechanics and Deep Underground Engineering, China University of Mining and Technology (Beijing), \\ Beijing 10083, China \\ ${ }^{2}$ Liaoning Research Institute for Nonferrous Metals, Shenyang 110000, China \\ ${ }^{3}$ Dazu Rock Carving Research Institute, Chongqing 402360, China
}

Correspondence should be addressed to Xuebin Cui; 2587429754@qq.com

Received 4 December 2020; Revised 22 December 2020; Accepted 2 January 2021; Published 12 January 2021

Academic Editor: Feng Xiong

Copyright (C) 2021 Zhigang Meng et al. This is an open access article distributed under the Creative Commons Attribution License, which permits unrestricted use, distribution, and reproduction in any medium, provided the original work is properly cited.

\begin{abstract}
Yuanjue Cave, located in Big Buddha Bay, Mount Baoding, Dazu Rock Carvings Area, has extremely high historical, artistic, and religious value and is an important grotto cultural relic in China. Due to the cutting action of the fissures and weak interlayers, the South Cliff of Big Buddha Bay where Yuanjue Cave is located showed signs of instability. In order to fully evaluate the stability of the rock mass around the cliff where Yuanjue Cave is located, a three-dimensional geological model of the surrounding rock of Yuanjue Cave was established by using FLAC3D software, combined with three-dimensional scanning, fissure investigation, and indoor tests. The stability of the surrounding rock mass adjacent to Yuanjue Cave has been studied by precise numerical simulation, and the results of numerical simulation and monitoring have been compared and analysed. The results show the following: (1) The west of J10 fissure, above the mudstone interlayer, is the main deformation area. The cliff displacement increases gradually from the east to the west. The independent block above the corner has the largest free space displacement, and there is a risk of independent collapse. Special attention should be paid to the stability of this block. The displacement of the upper monitoring point of the cliff wall is significantly greater than that of the lower layer. (2) In the surrounding rock block in the adjacent area, the various concentrated stresses of the body are mainly located at the entrance of Yuanjue Cave, the height of the chest of the Zhengjue Buddha statue, and the lower mudstone erosion and reinforcement zone. Among them, the stress concentration in the erosion and reinforcement area under the Zhengjue Buddha statue is the largest. The conclusions obtained can provide a useful reference for the stability assessment of the surrounding rock of Yuanjue Cave.
\end{abstract}

\section{Introduction}

The Yuanjue cave is the cultural relic category with the clearest inheritance, the closest relevance, the most complete system, the richest content, and the best preservation of authenticity and integrity in China. At the same time, they are also the most fragile cultural relics, and the state of preservation is closely related to geological and climatic conditions $[1,2]$. The geological bodies attached to the cultural relics in grottoes are always under the exogenic and endogenic forces of the earth and are also influenced by human activities. With the passage of time, grotto cultural relics will inevitably suffer from natural and man-made damage to a certain extent [3]. For example, the main problems facing the protection of the Dunhuang Mogao Grottoes include the fissures in the surrounding rock, severe weathering of the murals, and the burial of the caves by the accumulation of sand [4]; the main problems of the Longyou Grottoes include serious wall rock fissures, weathering, rain erosion, environmental pollution, etc. [5]; the main problems existing in the Bingling Temple Grottoes are the crevices of the cave cliffs and dangerous rocks, the seepage of the cliff walls of the caves, and the sedimentation of mud and sand in front of the caves [6]. These grottoes are rich in cultural heritage resources and are of high value in the field of national cultural heritage research, but most of them are seriously diseased and urgently need protection. In order to protect the long-term preservation of the grotto temples, Chinese 


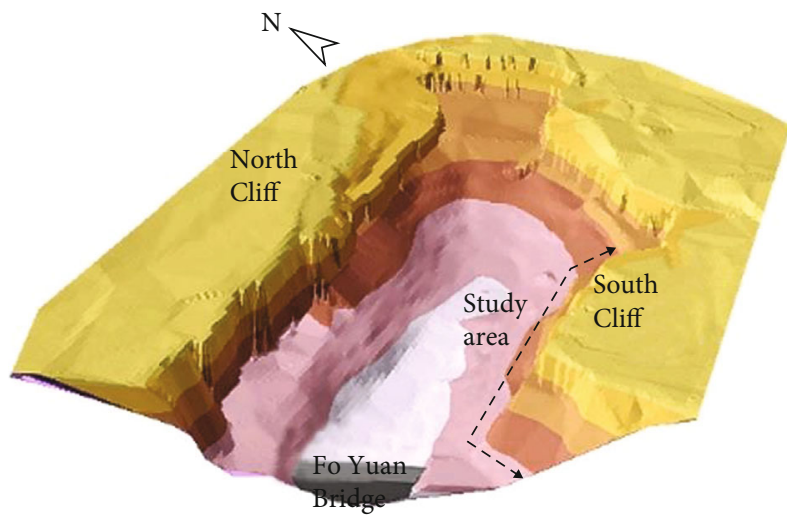

(a)

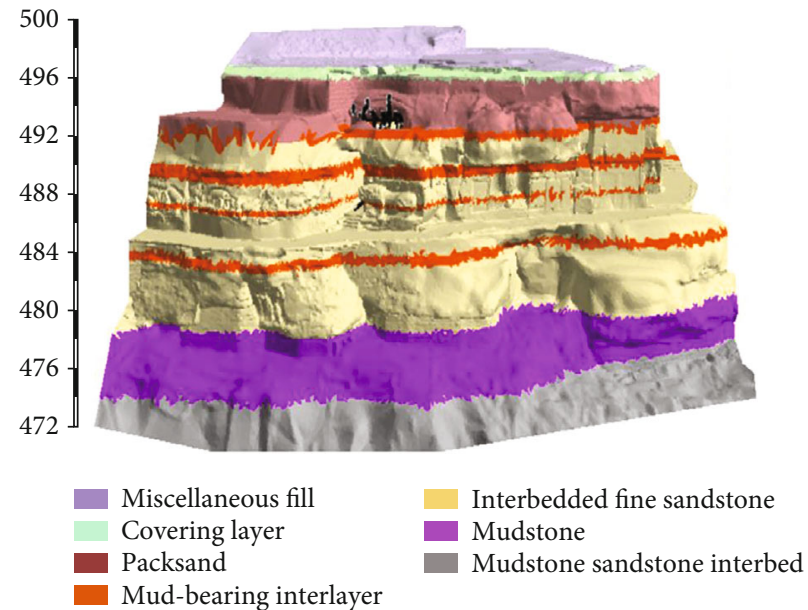

(b)

Figure 1: Topography and stratigraphic lithology of the gully in Big Buddha Bay: (a) three-dimensional topographic map of the Big Buddha Bay gully and (b) lithology section of the South Cliff of Big Buddha Bay.

scholars have carried out a lot of related research work. With the deepening of research, the protection of cave cultural relics has developed from the rescue and reinforcement stage to the scientific protection stage based on the study of the damage mechanism [7-14].

There are a large number of Buddhist and Taoist grottoes and cliff sculptures in Sichuan and Chongqing. These cave ruins have extremely high historical, artistic, scientific, social, and cultural value, and Dazu Rock Carvings is one of the most influential representative works. The main cliff carvings of Dazu Rock Carvings are concentrated in the Big Buddha Bay. The Big Buddha Bay is a natural ravine shaped like a horseshoe. The ancients used the natural cliff walls of the ravine to carve cliff statues. However, due to the development of joints and fissures in the surrounding rock of the Big Buddha Bay cliff, coupled with the effects of weathering, erosion, and water seepage, the overall stability of the cliff urgently needs scientific evaluation.

Since the 1970s, numerical simulation methods have been widely used in various fields of geotechnical engineering and occupy an important position in the analysis of rock mass stability [15-21]. However, due to the complexity of the spatial characteristics of the grotto cultural relics, the application of numerical simulation methods on it often fails to obtain good simulation results. On the basis of making full use of the work of predecessors, this paper establishes a high-precision threedimensional numerical analysis model of the complex fractured surrounding rock mass of Yuanjue Cave through a refined geological survey, three-dimensional scanning, engineering geophysical prospecting, and indoor testing. It provides a scientific basis for the stability management of Yuanjue Cave.

\section{Surrounding Rock Lithology and Fracture Structure Characteristics}

The gully of Big Buddha Bay is located in the branch of Longtangou, Mount Baoding, and the cliff wall is nearly upright, as shown in Figure 1(a). The gully strikes almost east-west and is formed by erosion from east to west. The overall shape is "U," with a length of more than 340 meters and a width of more than 90 meters. The valley bottom elevation is about $462-473 \mathrm{~m}$, and the cliff wall height is generally greater than $6 \mathrm{~m}$. The main rock formations of the South Cliff wall can be divided into four groups. The upper three groups are mainly composed of feldspar, quartz, and sandstone, belonging to the bottom of the Penglaizhen Formation of the Middle Jurassic; the lower rock layer is dominated by dark red mudstone and sandy mudstone, partially mixed with light gray to gray-green sandstone, which belongs to the top rock layer of the Suining Formation.

The overburden in the Big Buddha Bay area is the accumulation of loose artificial miscellaneous fill $\left(Q_{4}^{m l}\right)$, and the lower part is the typical "red bed" sandstone stratum in the Sichuan Basin of China. The stratum belongs to river-lacustrine facies deposits, dominated by interbedded horizontal fine-grained sandstone and mudstone. The stratum lithology changes strongly, and the alternating phenomenon of various sandstone and mudstone layers is prominent.

Due to the complex stratum of the surrounding rock mass where the cliff wall is located, the lithology and mechanical properties of each layer are quite different, so it is necessary to finely divide the stratum distribution through drilling and microscopic identification. After the fine division, there are 13 layers in total, as shown in Figure 1(b).

The lithology of the southern cliff is alternating between soft rock and hard rock, and there are 4 thin layers with weaker properties. Along these weak layers, intermittent horizontal interlayer cracks are formed. The horizontal layer is limited by the weak interlayer, and there are many points in the weak interlayer between the thin layers that are clamped or broken without cutting through the weak interlayer. Under the action of force, these weak layers are likely to be slightly displaced or weathered along the layers after being 


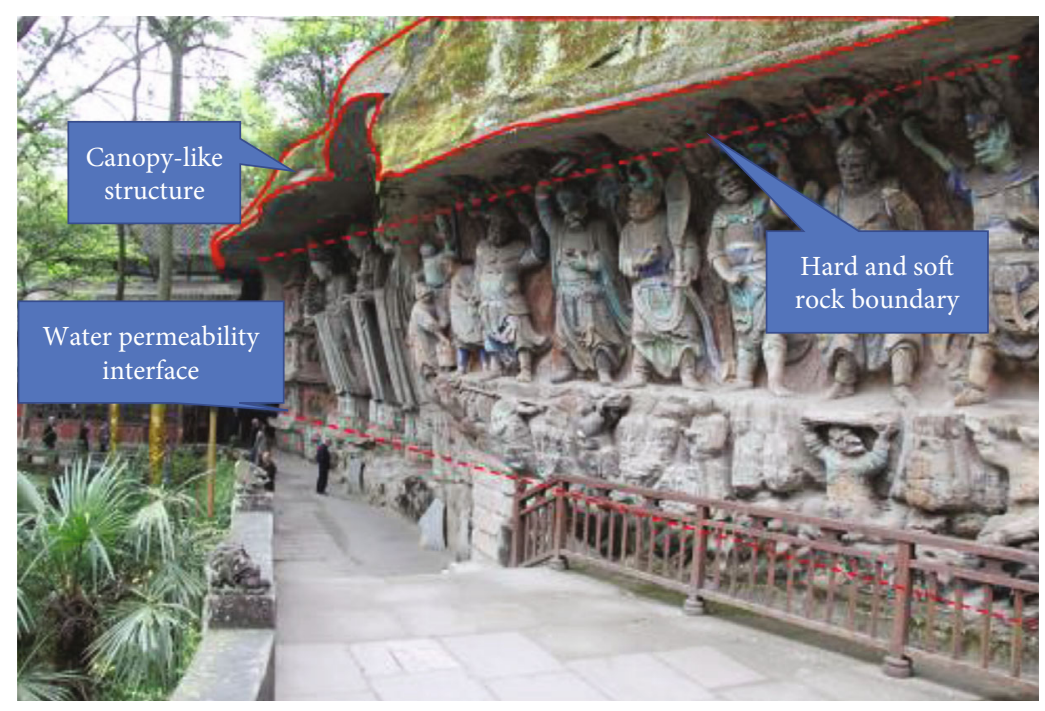

(a)
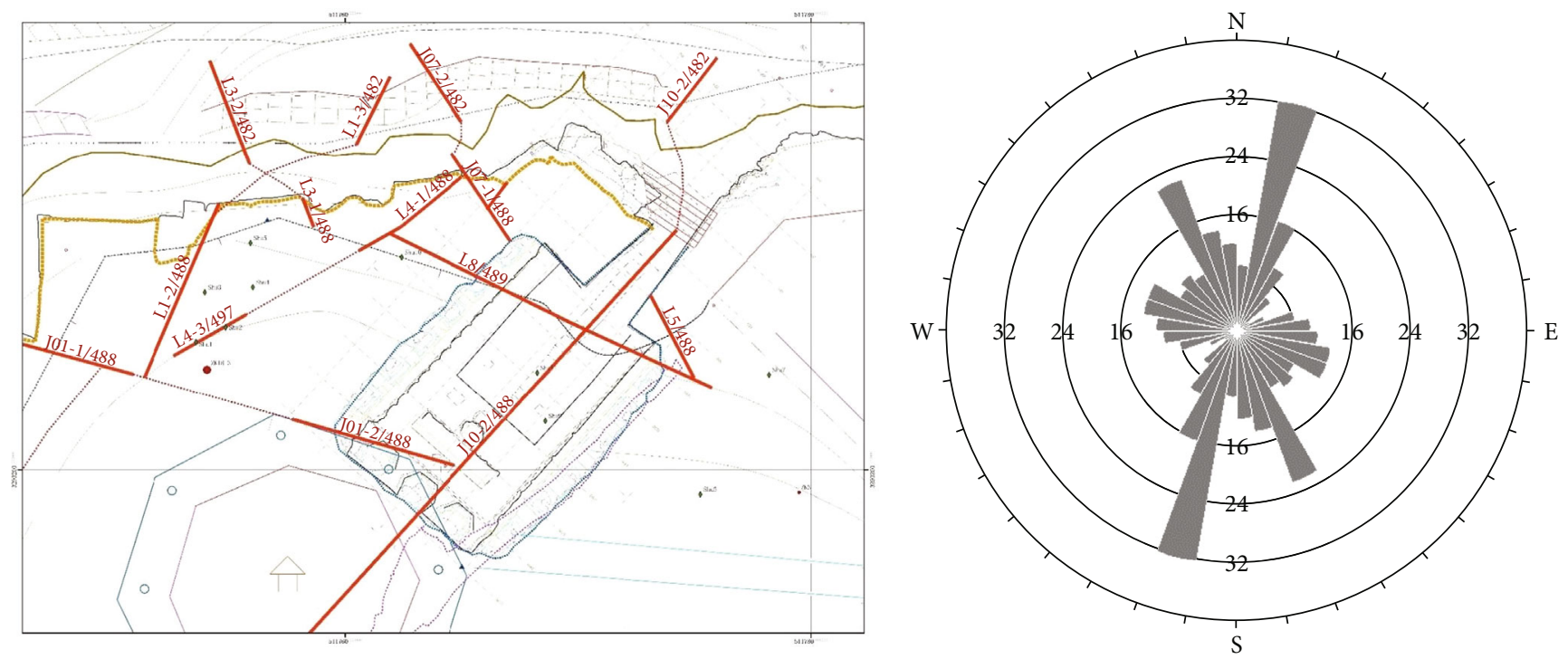

Legend

- Measured crack

..... Predicted crack

(b)

(c)

Figure 2: Characteristics of stratigraphy and fractures in the South Cliff of Big Buddha Bay: (a) the canopy structures; (b) fracture feature; (c) joint and fissure strike rosette.

subjected to geological structure or external weathering, gradually expand over time, and finally form nearly horizontal interlayer seepage in the entire area.

The rock formations of Big Buddha Bay are complex and changeable, forming a unique natural geographical landscape. The weak rock formations in the middle of the cliff wall are recessed under the action of weathering, so that the upper rock formations with good lithology form a prominent canopy-like structure. The sculptured statues of Big Buddha Bay are mainly located in the weak rock formations in the middle. The canopy-like structure formed by the upper rock layers protects the weaker statues in the lower layer and avoids direct wind and rain erosion, as shown in Figure 2(a).
The structural fissures on the cliff wall are also highly developed. There are altogether 13 fissures on the periphery of the study area of the South Cliff wall. There are 9 main cracks with a width of more than $3 \mathrm{~cm}$, including J-01, J-07, J-10, J-14, L1, L2, L4, L5, and L8, as shown in Figure 2(b).

Through statistical analysis of the occurrence of all fractures, it is found that there are mainly 3 groups of structural fractures around Yuanjue Cave, as shown in Figure 2(c).

The 3 groups of the structural fissures and the unloading fissures of the South Cliff wall, together with 4 weak interlayers, cut the rock mass around Yuanjue Cave and seriously affect the stability of the surrounding rock. At the same time, a large number of cut surrounding rock blocks make the analysis of its stability extremely difficult. 


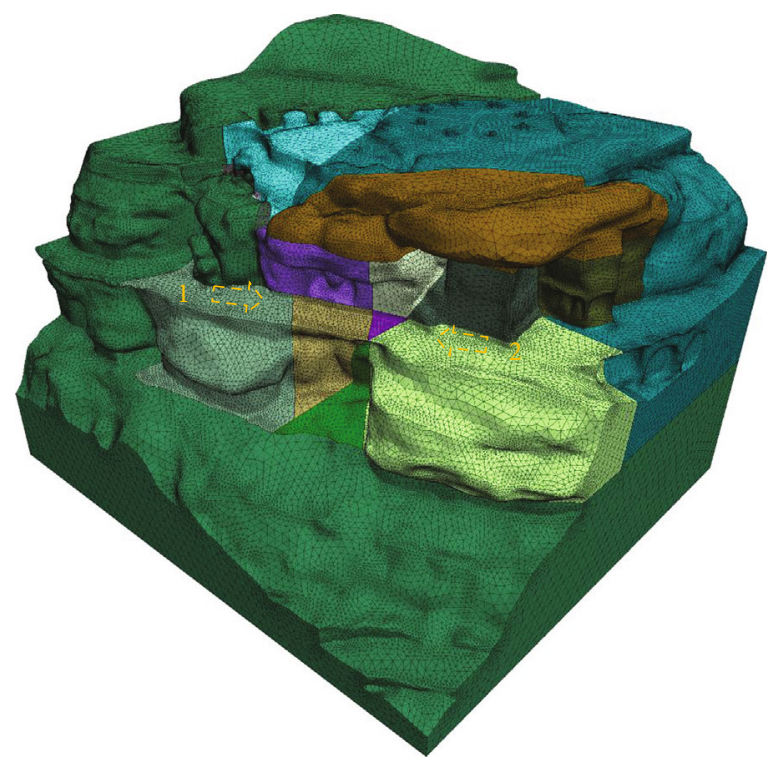

(a)

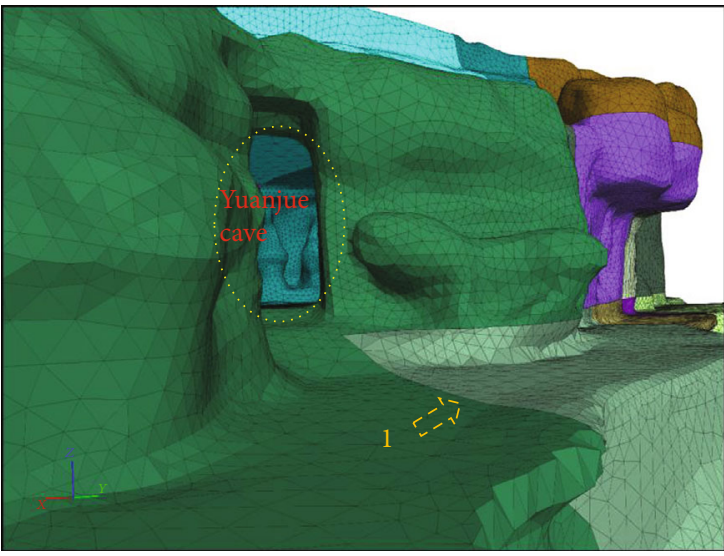

(b)

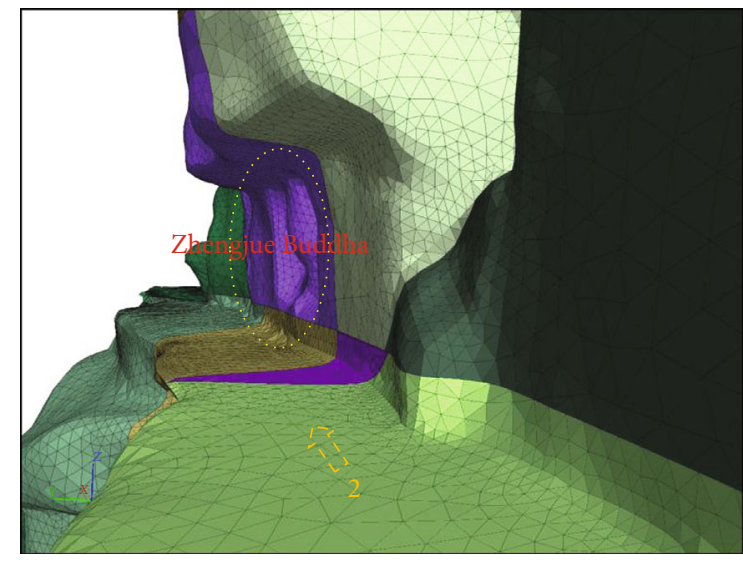

(c)

Figure 3: Computation model of rock mass and fissure: (a) three-dimensional geological model of the South Cliff of Big Buddha Bay; (b) east view of the South Cliff visitor passage; (c) west view of the South Cliff visitor passage.

\section{Numerical Simulation Analysis of Surrounding Rock Stability}

3.1. Solid Modeling of Fractures and Surrounding Rock. Based on the results of $3 \mathrm{D}$ laser scanning spatial point cloud data, the surface model modeling is completed, and on this basis, appropriate meshing is performed. The simulation range is based on the outer boundary of the unloading crack of the research object. The specific boundary layout is set as the east side of the model boundary to the middle of the cattle drawing, the west side is the cliff scan boundary, the south side is the J10 crack scan boundary ( $4 \mathrm{~m}$ from the base of the Wansui Building), the north side is the boundary of the cliff bottom scanning (valley bottom), and the lower part is more than $2 \mathrm{~m}$ from the lowest position of deep scanning. The size of the model is $46.4 \mathrm{~m}$ in the north-south direction, $40 \mathrm{~m}$ in the east-west direction, and $30 \mathrm{~m}$ high, as shown in Figure 3(a). And based on the fracture geological survey results, three-dimensional fractures are established in the solid model as shown in Figures 3(b) and 3(c).

\subsection{Physical and Mechanical Parameters and Boundary} Conditions. Based on the results of indoor rock tests, combined with the results of surrounding rock quality surveys, using the Hoek-Brown rock mass strength estimation criteria and regional experience comparison and analysis [22-24], the required calculation parameters are given. The formation parameters are shown in Table 1 . The initial stress field only considers the influence of the self-weight stress. There are 5 artificial cut boundaries in the model, of which the bottom boundary adopts $X / Y / Z$ three-directional constraints, and the two sides of the model adopt normal fixed boundaries. The fractured structural surface adopts contact surface elements, and the contact surface parameters are reduced and calculated according to the software formula according to the strength of the solid elements on both sides and the mesh 
TABLE 1: Mechanical parameters of surrounding rock.

\begin{tabular}{|c|c|c|c|c|c|c|c|}
\hline $\begin{array}{l}\text { Stratigraphic } \\
\text { sequence number }\end{array}$ & Stratum & $\begin{array}{c}\text { The depth of the } \\
\text { strata }(\mathrm{m})\end{array}$ & $\begin{array}{c}\text { Elasticity } \\
\text { modulus }(\mathrm{Pa})\end{array}$ & $\begin{array}{l}\text { Poisson's } \\
\text { ratio }\end{array}$ & $\begin{array}{c}\text { Cohesive } \\
\text { strength }(\mathrm{Pa})\end{array}$ & $\begin{array}{c}\text { Internal } \\
\text { friction angle } \\
\left(^{\circ}\right)\end{array}$ & $\begin{array}{c}\text { Soil natural } \\
\text { density }\left(\mathrm{kg} / \mathrm{m}^{3}\right)\end{array}$ \\
\hline 1 & Miscellaneous fill & $25.2-70$ & $1.00 \times 10^{9}$ & 0.41 & $2.50 \times 10^{4}$ & 18 & 1660 \\
\hline 2 & Packsand & $22.3-25.2$ & $2.76 \times 10^{10}$ & 0.17 & $1.35 \times 10^{6}$ & 33 & 2230 \\
\hline 3 & $\begin{array}{l}\text { Interbedded fine } \\
\text { sandstone }\end{array}$ & $21.8-22.33$ & $1.38 \times 10^{10}$ & 0.25 & $9.00 \times 10^{5}$ & 34 & 2150 \\
\hline 4 & Packsand & $20.1-21.8$ & $2.50 \times 10^{10}$ & 0.18 & $1.50 \times 10^{6}$ & 32 & 2200 \\
\hline 5 & $\begin{array}{l}\text { Interbedded fine } \\
\text { sandstone }\end{array}$ & $19.23-20.1$ & $1.38 \times 10^{10}$ & 0.25 & $9.00 \times 10^{5}$ & 33 & 2040 \\
\hline 6 & Packsand & $15.67-19.23$ & $2.50 \times 10^{10}$ & 0.18 & $1.50 \times 10^{6}$ & 35 & 2240 \\
\hline $6-1$ & $\begin{array}{l}\text { Argillaceous fine } \\
\text { sandstone }\end{array}$ & $15.38-15.67$ & $1.00 \times 10^{10}$ & 0.3 & $6.00 \times 10^{5}$ & 33 & 2160 \\
\hline 7 & $\begin{array}{l}\text { Argillaceous fine } \\
\text { sandstone }\end{array}$ & $14.74-15.38$ & $1.00 \times 10^{10}$ & 0.3 & $6.00 \times 10^{5}$ & 32 & 2230 \\
\hline 8 & Packsand & $10.72-14.74$ & $2.50 \times 10^{10}$ & 0.18 & $1.50 \times 10^{6}$ & 34 & 2270 \\
\hline $8-1$ & Packsand & $7.82-10.72$ & $2.50 \times 10^{10}$ & 0.18 & $1.50 \times 10^{6}$ & 36 & 2210 \\
\hline 9 & Mudstone & $7.34-7.82$ & $6.00 \times 10^{9}$ & 0.35 & $8.00 \times 10^{5}$ & 37 & 2360 \\
\hline 10 & Packsand & $6.61-7.34$ & $2.50 \times 10^{10}$ & 0.18 & $1.50 \times 10^{6}$ & 38 & 2160 \\
\hline 11 & Mudstone & $5.35-6.61$ & $6.00 \times 10^{9}$ & 0.35 & $8.00 \times 10^{5}$ & 39 & 2310 \\
\hline 12 & Packsand & $4.33-5.35$ & $2.50 \times 10^{10}$ & 0.18 & $1.50 \times 10^{6}$ & 42 & 2350 \\
\hline 13 & Mudstone & $-3.2-4.33$ & $6.00 \times 10^{9}$ & 0.35 & $8.00 \times 10^{5}$ & 32 & 2260 \\
\hline
\end{tabular}

TABLe 2: Wansui Building load statistic table.

\begin{tabular}{lcccc}
\hline Project & Evaluation & Unit & Quantity & Calculated load value (kN) \\
\hline Bedding live load & 3.6 & $\mathrm{kN} / \mathrm{m}^{2}$ & 112.37 & 404.53 \\
Constant load (converted into wood) & 550 & $\mathrm{~kg} / \mathrm{m}^{3}$ & 78.66 & 432.62 \\
Glazed tile (containing a blanket) & 174.3 & $\mathrm{~kg} / \mathrm{m}^{2}$ & 278.872 & 486.07 \\
Coloured glaze vertical ridges & 94.5 & $\mathrm{~kg} / \mathrm{m}$ & 96.576 & 91.26 \\
Total & & & & 1414 \\
Average load of each column & & & 177 \\
\hline
\end{tabular}

size. After establishing the constrained boundary, the linear elastic model is first used to perform self-balance under the gravitational field conditions, and then, it enters the elastoplastic stage calculation of the Mohr-Coulomb ideal elastoplastic model. The specific parameters of the formation are shown in Table 1.

3.3. Calculation and Application of Additional Load. The Wansui Building was built in 1412, Ming Dynasty, which is the main additional load on the surrounding rock masses. The relative positions of the columns of the Wansui Building and Yuanjue Cave are shown in Figures 2 and 3. The Wansui Building is an octagonal wooden tower structure with a height of $21.2 \mathrm{~m}$ and a bottom side width of $3.6 \mathrm{~m}$. It is located directly behind the upper part of Yuanjue Cave and straddles the J10 fissure. The columns on the east and north sides are located above the fissure cavity of J10, and the col- umn in the southeast direction is located on the roof of Yuanjue Cave and is $0.7 \mathrm{~m}$ away from the rock wall. According to the relevant load value standards of ancient buildings, the load of the Wansui Building is counted. The relevant load values are shown in Table 2.

According to the calculation of the load and distribution characteristics of the table, the load of the Wansui Building is mainly distributed on the inner circle column. At the same time, according to the cross-sectional area of the column, the load is converted into a normal (vertical) pressure value $(200 \mathrm{kPa})$ for application.

3.4. Characteristics of the Surrounding Rock Stress Field. The analysis object mainly includes two aspects of stress concentration and stress deflection. In terms of stress concentration, three stress cloud maps of $z z / y y / x x$ (vertical/north-south/east-west) are selected, two planes of $x y / x z$ are selected for 

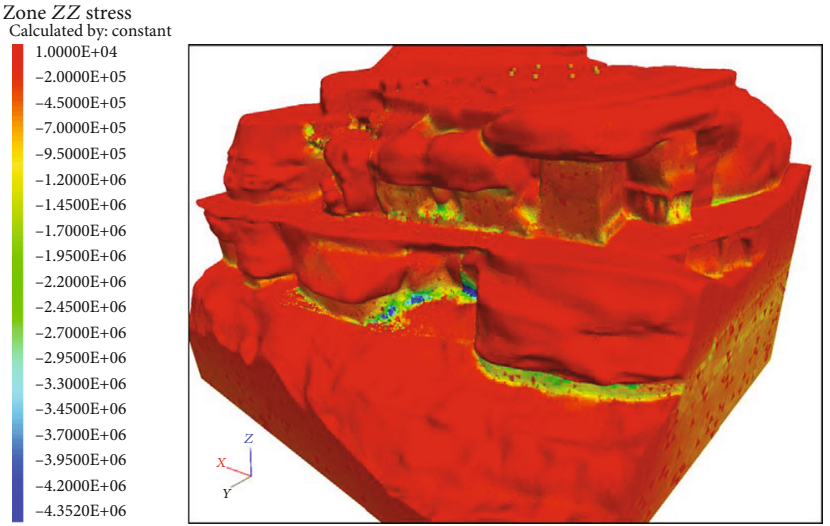

(a)

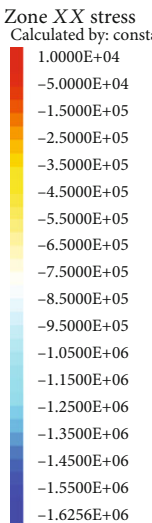

$-1.6256 \mathrm{E}+06$

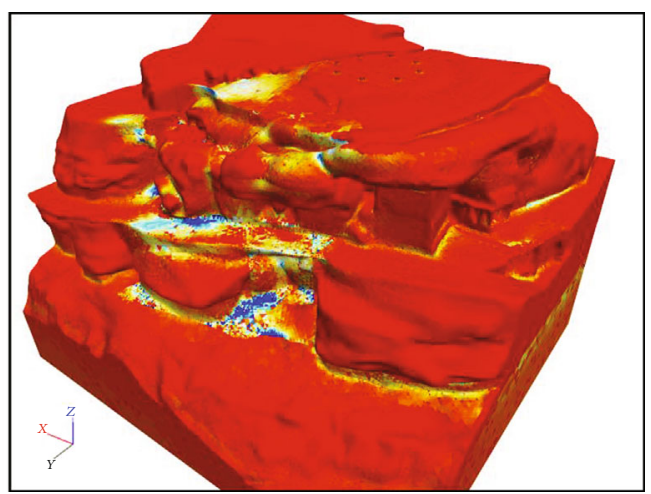

(c)

Zone $X Z$ stress

Calculated by: consta
$6.8902 \mathrm{E}+05$
$6.3000 \mathrm{E}+05$
$5.7000 \mathrm{E}+05$
$5.1000 \mathrm{E}+05$
$4.5000 \mathrm{E}+05$
$3.9000 \mathrm{E}+05$
$3.3000 \mathrm{E}+05$
$2.7000 \mathrm{E}+05$
$2.1000 \mathrm{E}+05$
$1.5000 \mathrm{E}+05$
$9.0000 \mathrm{E}+04$
$3.0000 \mathrm{E}+04$
$-3.0000 \mathrm{E}+04$
$-9.0000 \mathrm{E}+04$
$-1.5000 \mathrm{E}+05$
$-2.1000 \mathrm{E}+05$
$-2.1000 \mathrm{E}+05$
$-3.3000 \mathrm{E}+05$
$-3.8663 \mathrm{E}+05$

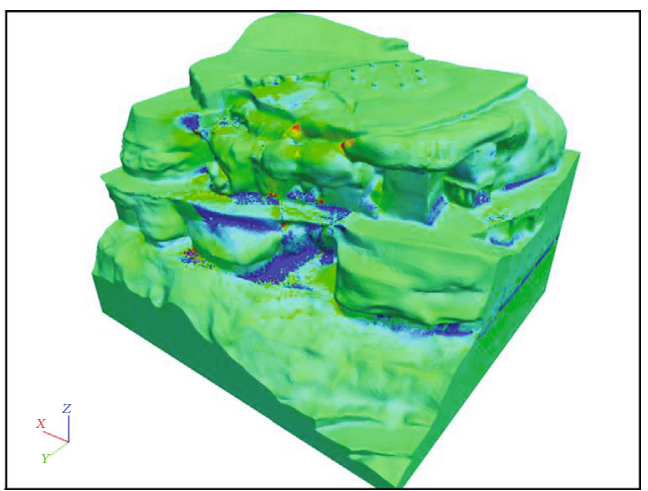

(e)
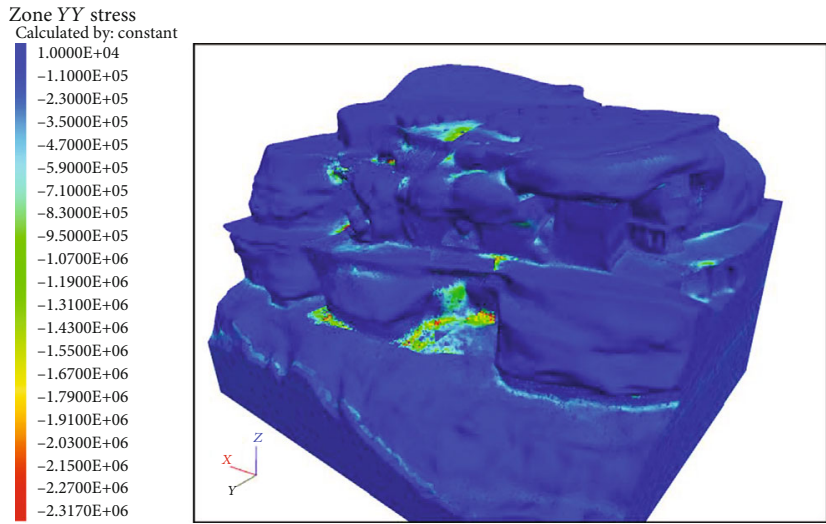

(b)

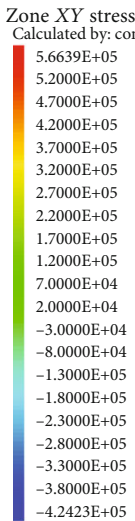

$-3.8000 \mathrm{E}+05$
$-4.2423 \mathrm{E}+05$

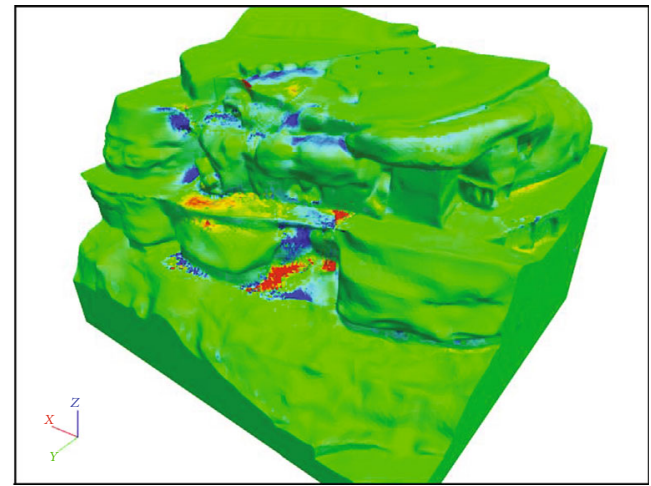

(d)

Zone minimum principal stress

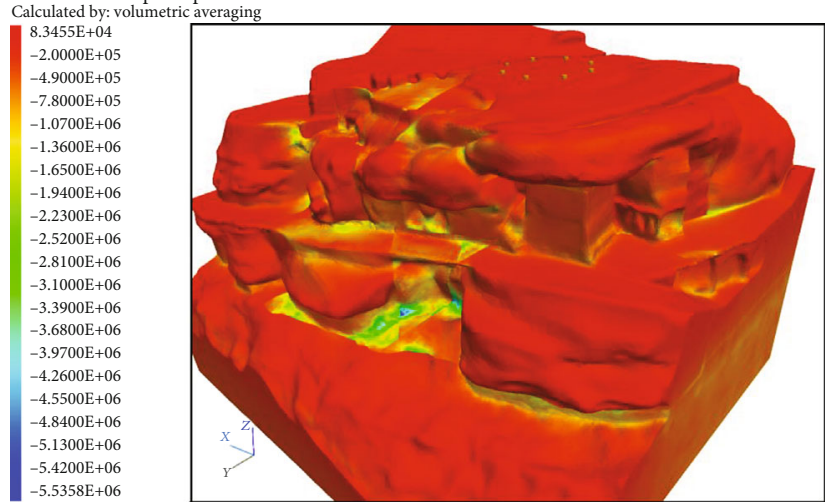

(f)

FIGURE 4: Stress nephogram contour of surrounding rock: (a) ZZ stress nephogram; (b) $Y Y$ stress nephogram; (c) $X X$ stress nephogram; (d) $X Y$ stress nephogram; (e) $X Z$ stress nephogram; (f) maximum principal stress nephogram.

shear stress, and the maximum principal stress is selected as the analysis object for principal stress.

In terms of vertical stress (Figure 4(a)), the results show that it is mainly concentrated on two steps. The upper level is the visitor passage, which belongs to the lower part of the statue. It is mainly due to the local stress concentration formed by the excavated rock mass of the statue. The lower steps are located in the mudstone weathering groove belt, and the belt grooves also lead to the belt concentration of vertical stress.

In terms of horizontal stress, the stress distribution characteristics in the two horizontal directions of $y y / x x$ (north- south/east-west) are basically the same (Figures 4(b) and $4(c)$ ), except that the vertical stress is concentrated on two steps. In addition to the characteristics, the horizontal stress concentration is obvious at the top plate of Yuanjue Cave, which is mainly caused by the horizontal tension and compression stress caused by the hanging of the top plate of Yuanjue Cave.

In terms of shear stress distribution, analysis of the two typical $x y / x z$ plane shear stresses (Figures $4(\mathrm{~d})$ and $4(\mathrm{e})$ ) shows that the shear stress is mainly distributed in areas with dense cracks, such as near the Zhengjue Buddha statue. This 


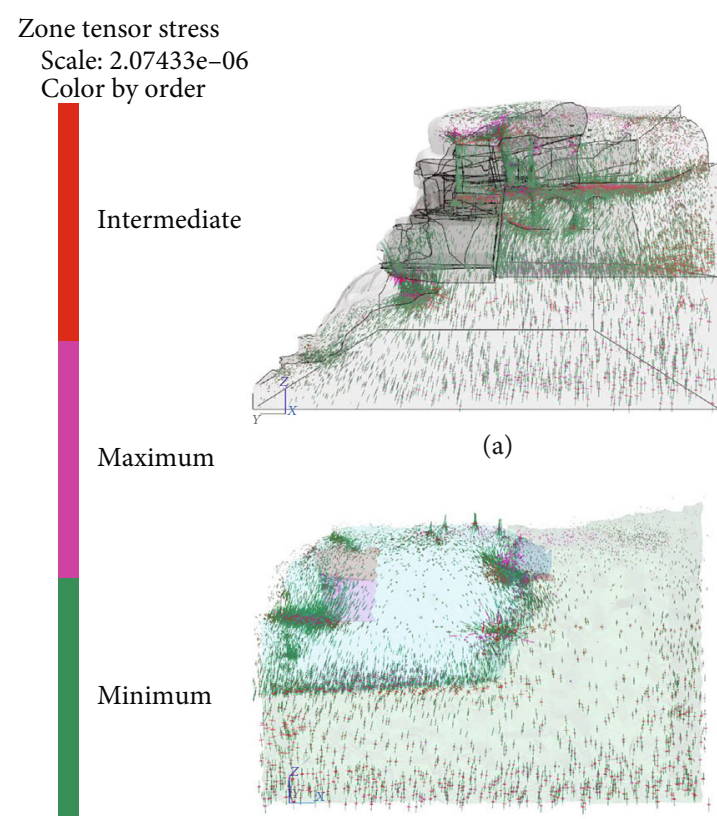

(d)

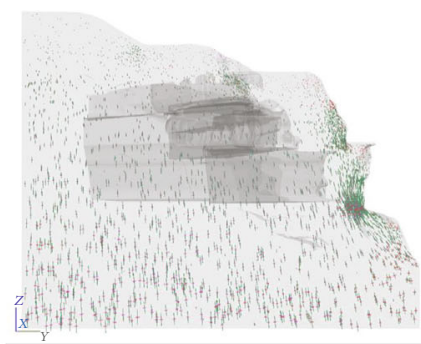

(b)

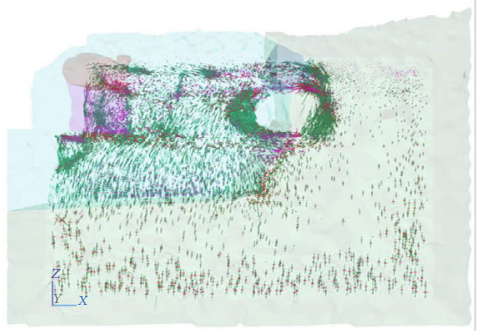

(e)

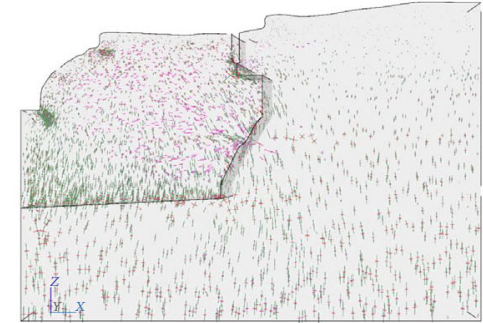

(c)

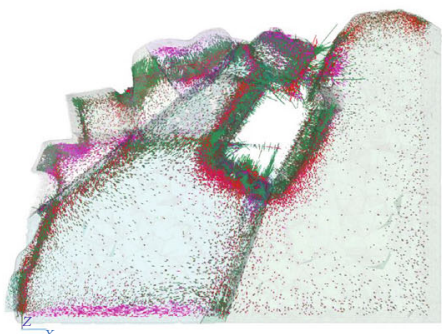

(f)

FIGURE 5: Stress trajectory of surrounding rock: (a) $X=2 \mathrm{~m}$; (b) $X=46 \mathrm{~m}$; (c) $Y=1 \mathrm{~m}$; (d) $Y=5 \mathrm{~m}$; (e) $Y=15 \mathrm{~m}$; (f) $Z=15 \mathrm{~m}$.

feature indicates that the surrounding rock fissures, especially those near the Zhengjue Buddha statue, bear most of the cliff shear stress.

The distribution of the maximum principal stress is shown in Figure 4(f). The distribution of the maximum principal stress combines the characteristics of the aforementioned subcomponent stresses, presents the characteristics associated with the distribution of cracks, the weak layers, and the shape of the cliff wall, and forms a concentrated area around Yuanjue Cave and the Zhengjue Buddha statue.

The surrounding rock stress trace is based on the calculation of the three principal stress directions of the element body, including the maximum principal stress, the intermediate principal stress, and the minimum principal stress. The trace of each element is represented by three orthogonal short lines in space. The length indicates the absolute value of the stress. When the space size and boundary conditions change, the three principal stresses inside the rock and soil mass will undergo stress deflection. Select 6 representative cross sections $X=2$ and $46 \mathrm{~m}, Y=1,5$, and $15 \mathrm{~m}$, and $Z=$ $15 \mathrm{~m}$ for analysis, as shown in Figure 5 .

For the $X=2$ and $X=46 \mathrm{~m}$ section, it represents the distribution of stress traces on the east and west sides of the model. The results show that the principal stress traces of the slope near the slope of the rock mass will be significantly deflected. And the general feature is that the closer to the slope, the closer the maximum principal stress is to the empty surface of the slope parallelly and the closer the minimum principal stress is to the slope surface orthogonally. At the junction of the blocks and the recessed parts of the undercut reinforcement, there is obvious stress concentration.

For the $Y=1$ to $5 \mathrm{~m}$ section, the results show that the maximum principal stress in the rock mass is dominated by vertical stress, but the direction of the principal stress at the boundary of the rock mass is deflected, and it can be found that the direction of the principal stress at the J10 fracture is obviously deflected, and finally, the fracture interface is perpendicular. At $Y=15 \mathrm{~m}$, affected by the excavation of Yuanjue Cave, a stress deflection circle is formed around Yuanjue Cave. The principal stress in the rock mass on the west side of the cavern appears uniformly deviated, and the maximum principal stress forms an angle of approximately $45^{\circ}$ with the horizontal plane.

For the $Z=15 \mathrm{~m}$ cross section, it is parallel and penetrates the imaging horizon. The results show that there is a general stress deflection and concentration phenomenon at the boundary cracks of the rock mass in the adjacent area of Yuanjue Cave. This phenomenon has also led to the complex interaction between the rock masses surrounding the cliff wall.

3.5. Characteristics of the Surrounding Rock Displacement Field. Figure 6(a) is the overall displacement cloud diagram of the cliff block. Although the cliff wall is composed of many independent cut blocks, there is a certain degree of displacement discontinuity between the blocks, but the overall consistency is still high. Taking the J10 fissure and the bottom mudstone layer as the displacement boundary, the displacement of the rock mass east of the J10 fissure and below the mudstone layer is extremely small. Therefore, the J10 fissure can be regarded as the boundary that controls the stability of the cliff wall from east to west, and the lower mudstone layer can be regarded as the bottom boundary of the cliff wall deformation.

In the area where the deformation of the cliff wall is relatively large, there is a transition area in the displacement under Yuanjue Cave and the lower portion of the Zhengjue Buddha statue. The amount of displacement increases from small to east from west to east in the horizontal direction 


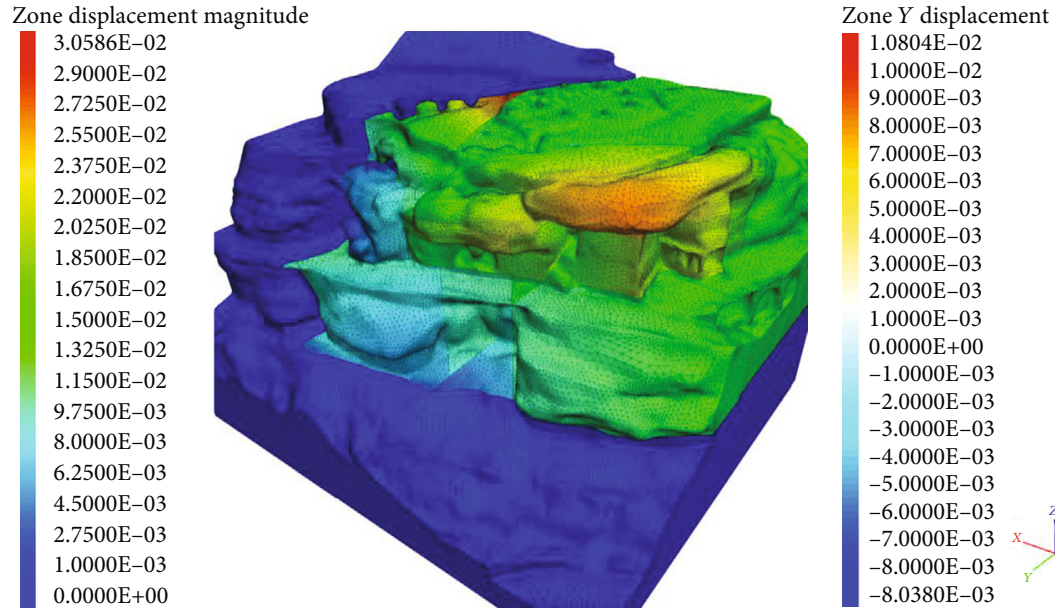

(a)

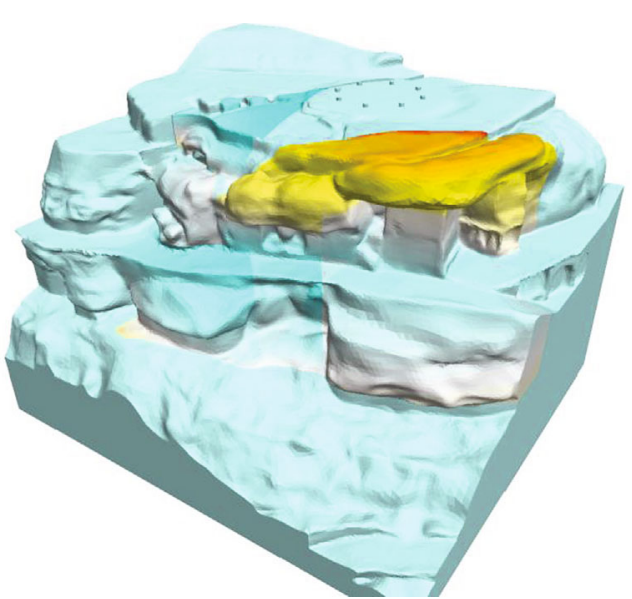

(b)

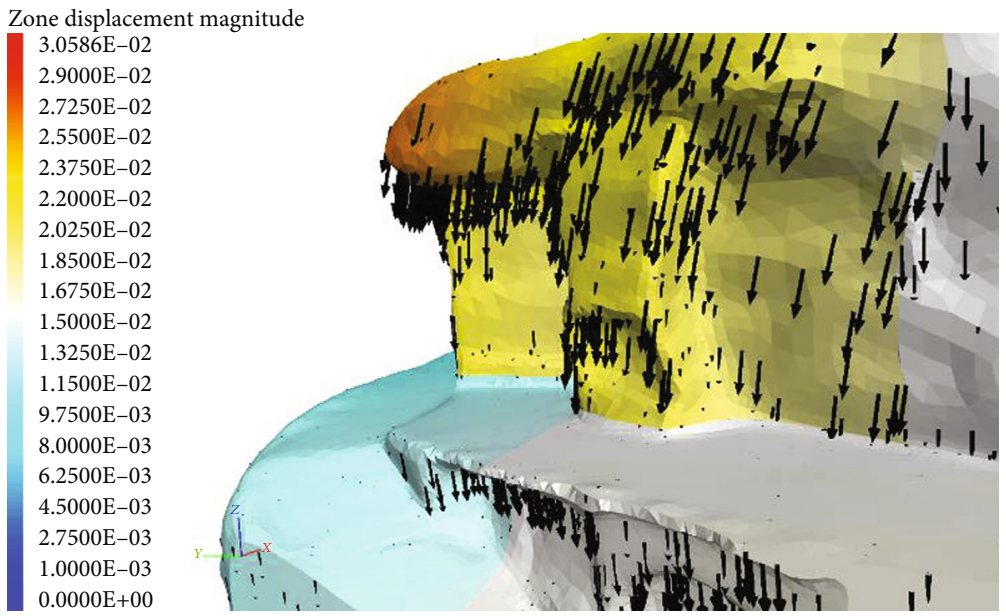

(c)

FIGURE 6: Displacement nephogram contour of surrounding rock: (a) total displacement cloud map; (b) south-north ( $Y$ direction) displacement cloud map; (c) displacement vector field at the corner of the cliff wall.

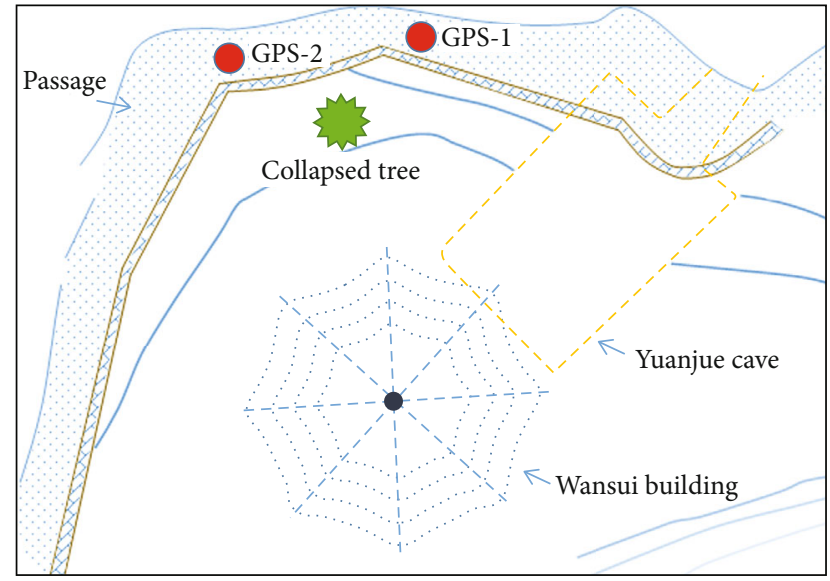

FIGURE 7: Monitoring site layout.

and gradually increases from bottom to top in the vertical direction. Changes in the two directions converge at the top of the cliff corner and reach a peak. The maximum displace- ment here is $30.586 \mathrm{~mm}$. Due to the existence of double-faced voids on the cliff wall, this kind of deformation law also conforms to the basic deformation law of rock mechanics. However, due to fracture cutting and control, the deformation between the cliff wall blocks is discontinuous.

Figure 6(b) is the displacement cloud map in the $Y$ direction (south-north direction) of the model. The figure shows that the displacement of the independent block at the corner of the cliff wall and the surrounding rock mass are more obvious. The maximum value in the $Y$ direction is $10.804 \mathrm{~mm}$, and the displacement is biased towards the cliff. The displacement vector in Figure 6(c) also shows this trend. It can be seen that the rock mass above the cliff has a certain horizontal deflection angle and is biased to the side of the cliff.

\section{Monitoring and Verification of Surrounding Rock Deformation}

4.1. Displacement Monitoring Layout. In order to verify the law of surrounding rock deformation, based on the aforementioned numerical simulation results, two GNSS 


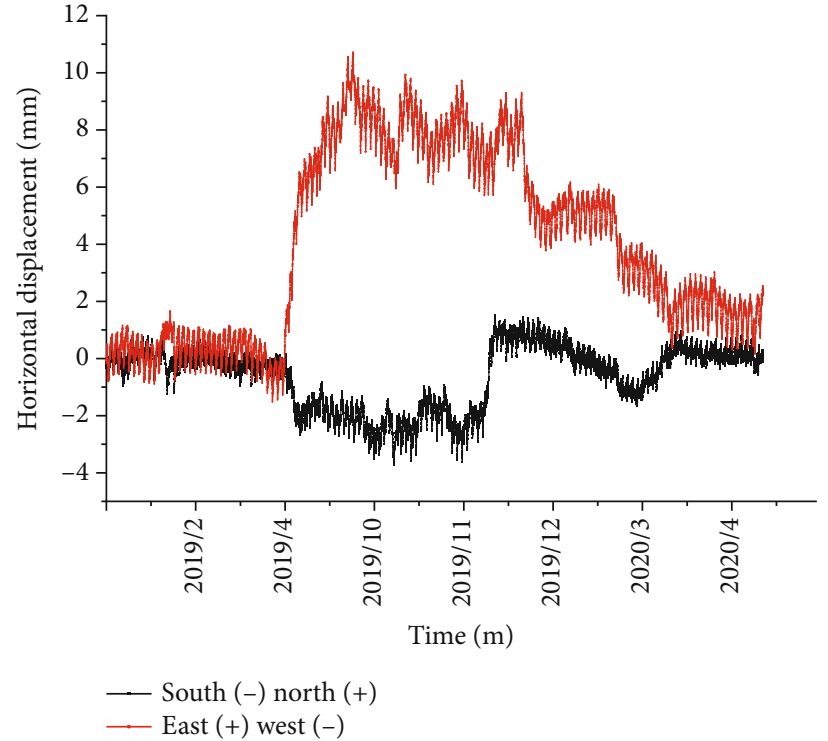

(a)

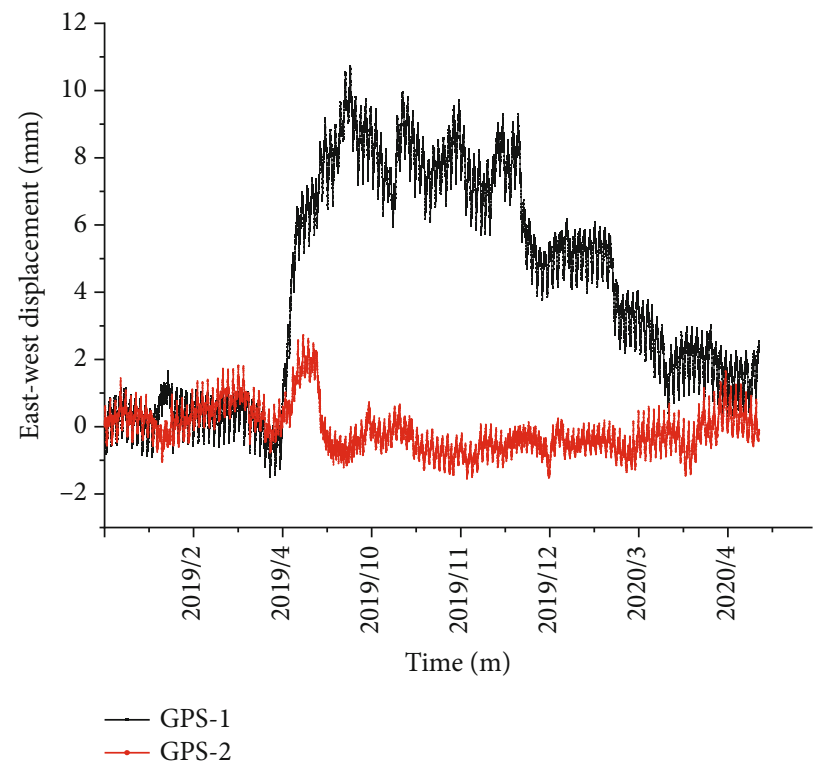

(c)

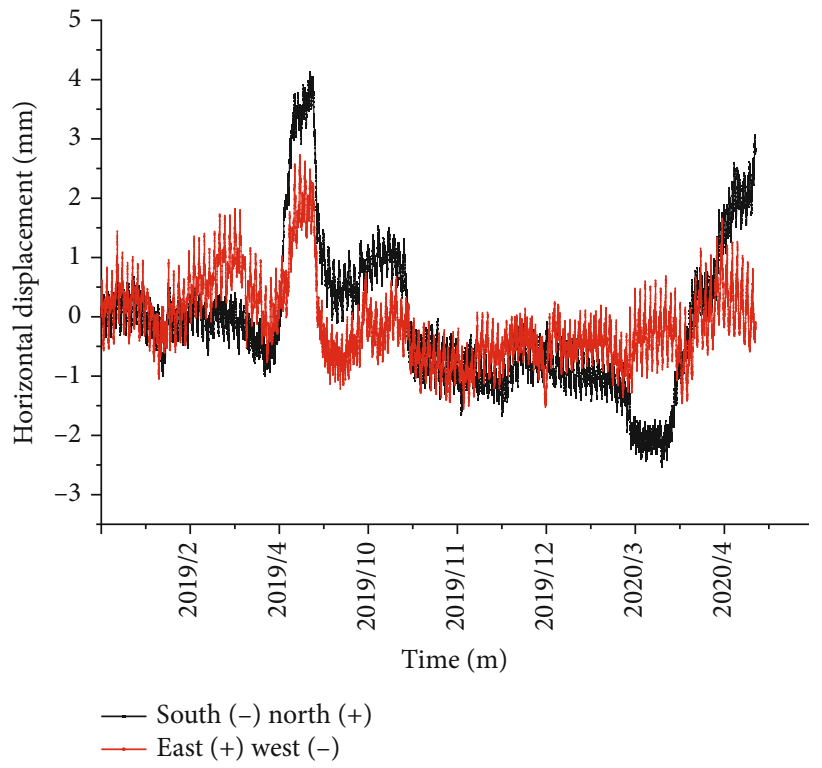

(b)

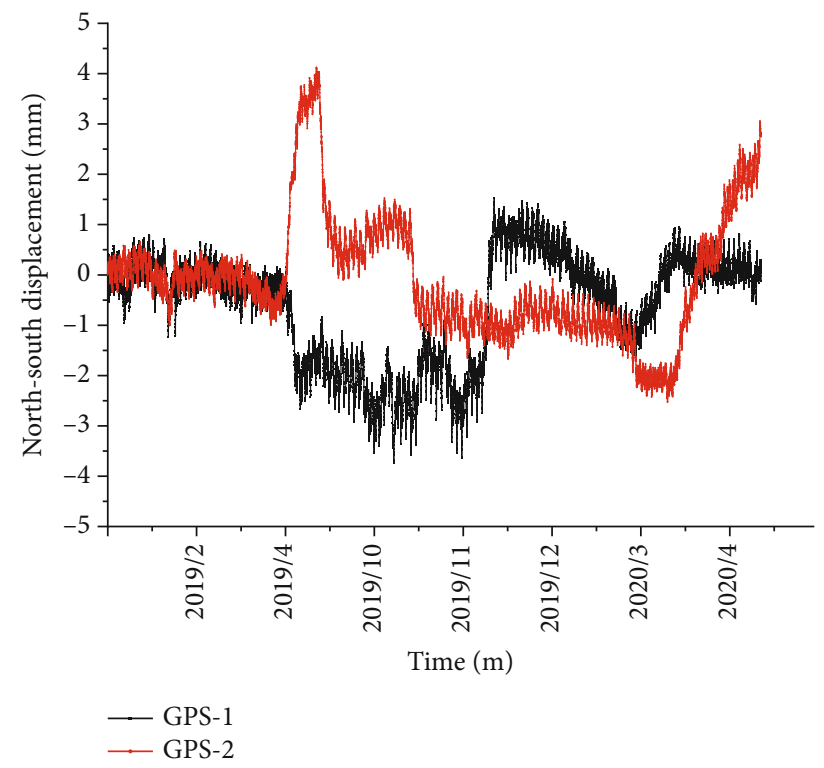

(d)

FIGURE 8: In situ monitoring data: (a) horizontal displacement of the GPS-1 displacement monitoring point; (b) horizontal displacement of the GPS-2 displacement monitoring point; (c) comparison of east-west displacement of the GPS1/GPS2 monitoring point; (d) comparison of the north-south displacement of the GPS1/GPS2 monitoring point.

displacement monitoring points are set up at the corners of the deformed cliff and the transition section (above the Zhengjue Buddha statue). It is planned to collect more than 5 years of monitoring data to verify the characteristics of rock mass displacement near the cliff top. The GNSS monitoring point is a star-level radio positioning system, the monitoring collection frequency is 2 times/h, the plane resolution accuracy is $2.5 \mathrm{~mm}+1 \times 10^{-6} \mathrm{D}$, and the elevation resolution accuracy is $2.5 \mathrm{~mm}+1 \times 10^{-6} \mathrm{D}$. The layout of monitoring points is shown in Figure 7.

4.2. Data Analysis and Verification. Due to the age of excavation at the Big Buddha Bay statue site, the impact of the exca- vation process and unloading on the cliff wall has basically stabilized. However, there are still factors such as visitor dynamic load, accidental load, periodic action of fissure water pressure, and soft mudstone creep at the bottom that affect the cliff wall deformation. The deformation process of the rock mass surrounding the cliff wall of Big Buddha Bay is a process with extremely long periods and restricted by many factors. Therefore, the changes described by the monitoring data can only be used to verify the numerical simulation results in the trend, but they cannot be compared with the simulation results in the numerical value.

The installation of the GNSS monitoring point was completed in February 2019. The GPS-2 monitoring point 
is located at the corner of the cliff, and the GPS-1 monitoring point is located between the corner of the cliff and Yuanjue Cave.

Since the horizontal data of GNSS monitoring points are more accurate than the vertical data, two horizontal monitoring data of "south-north" and "east-west" are selected for analysis. Comparing Figures 8(a) and 8(b) during the period from $2019 / 4$ to $2019 / 9$ to the two monitoring points, the fluctuation range of the monitoring data was beyond the normal range $( \pm 1 \mathrm{~mm})$, but the variation range of the no. 1 monitoring point is greater than that of the no. 2 monitoring point, and the maximum amount of change in the east-west direction reaches $10 \mathrm{~mm}$.

This phenomenon is due to the strong wind and rain in the area on June 3 during the period of 2019/4-2019/9, which caused a large tree with a diameter of $35-45 \mathrm{~cm}$ at breast height within $5 \mathrm{~m}$ from the corner of the cliff wall to fall to the northeast; the root rock mass is close to the no. 2 monitoring point, causing displacement of the adjacent rock mass at the corner of the cliff wall, while the no. 1 monitoring point is relatively far away, so the two values are quite different. This also verifies the view that the cliff wall deformation is affected by the interaction of the blocks in the numerical analysis results. The surrounding rock masses at the two monitoring points are cut by the fissures and are independent of each other. They are in a state of lap joint. The structure is unstable, so a large displacement mutation occurs under the action of dynamic load (the falling of a big tree).

From the comparison of the east-west displacement of the monitoring point in Figure 8(c), it can be seen that the accidental factor of the tree tipping is the main factor leading to the east-west displacement, and it has gradually recovered and stabilized.

As shown in Figure 8(d), in terms of the north-south displacement, the monitoring curve also changes greatly after the tree tipping time, but the amount of change is significantly smaller. On the other hand, different from the eastwest displacement, the north-south displacement has obvious fluctuation characteristics with the arrival of the tourist season (for example, National Day), and the fluctuation range is between 3 and $5 \mathrm{~mm}$, because all the tourists entering the venue need to gather and pass through the cliff steps; this rule is obviously related to the periodic changes of tourist load.

In short, due to the constraints of objective conditions, the on-site monitoring results and the numerical simulation results have regular consistency, which verifies the correctness and reliability of the simulation results. With the deepening of work and the discovery of problems, we will set up more monitoring points for monitoring and verification of results in view of the progress of the research on the stability of the surrounding rock wall of Yuanjue Cave and provide technical support for the protection of cultural relics.

\section{Conclusion}

Through accurate numerical simulation research on the stability of surrounding rock near Yuanjue Cave, the numerical simulation results are compared with the on-site monitoring results. The main conclusions are as follows:

(1) The main deformation zone is to the west of the J10 fissure and above the mudstone interlayer. The displacement of the cliff wall gradually increases from the east to the west, and the displacement and deformation value from the middle corner to the empty side of the cliff is larger. The "lotus"-independent block has the largest displacement near the air, and there is a risk of independent collapse. The displacement of the upper monitoring point is significantly larger than that of the lower monitoring point

(2) Various stresses in the surrounding rock block of Yuanjue Cave are mainly concentrated at the entrance of Yuanjue Cave, the height of the chest of the Zhengjue Buddha statue, and the lower mudstone erosion reinforcement zone. The stress concentration in the erosion reinforcement area under the Zhengjue Buddha statue is the largest, the lower part of the J10 fracture (there is stress concentration on both sides of the rock mass contact zone). The upper cliff wall is cut into an independent deformation zone in the lower mudstone undercut layer and the J10 fissure. There are stress concentration and stress deflection phenomena in the contact parts of the blocks

(3) A stress deflection circle is formed around Yuanjue Cave, and the principal stress deflection appears in the rock mass on the west side of Yuanjue Cave, which tends to the side of the cliff wall

(4) By comparing the on-site measurement results with the numerical analysis results, it can be seen that the monitoring data partially validated the numerical simulation results, indicating that the parameters used in the numerical simulation are appropriate and the deformation law of surrounding rock obtained by simulation can be used to guide the protection of Dazu Rock Carvings

\section{Data Availability}

The data are available and explained in this article; readers can access the data supporting the conclusions of this study.

\section{Conflicts of Interest}

The authors declare no conflict of interest.

\section{Authors' Contributions}

The manuscript is approved by all authors for publication.

\section{Acknowledgments}

This work was supported by Dazu District Science and Technology Commission Project Funding (No. DZKJ2018ABB1011). 


\section{References}

[1] K. Z. Huang, "Thoughts on the protection of stone cultural relics," Chinese Cultural Heritage, vol. 86, no. 4, pp. 6-14, 2018.

[2] Z. G. Tao, M. N. Li, and C. Zhu, "Analysis of the critical safety thickness for pretreatment of mined-out areas underlying the final slopes of open-pit mines and the effects of treatment," Shock and Vibration, no. 2, pp. 1-8, 2018.

[3] R. Zhang, "Analysis and research on the protection planning of Chinese cave temples," Chinese Cultural Heritage, vol. 4, pp. 49-60, 2018.

[4] X. D. Wang, M. Q. Zhang, H. Y. Zhang, Z. Z. Zeng, Z. Yao, and Z. H. Zhou, "Engineering properties of surrounding rocks of Mogao grottoes at Dunhuang," Chinese Journal of Rock Mechanics and Engineering, vol. 6, pp. 756-761, 2000.

[5] Z. Jiewang, C. Zhonghua, L. Encong, Z. H. Luqing, and Y. A. Zhifa, "Failure causes and reinforcement countermeasures for no.1 grotto of Longyou grottoes," Journal of Engineering Geology, vol. 17, no. 1, pp. 126-132, 2009.

[6] Y. Wang, B. Zhang, S. H. Gao, and C. H. Li, "Investigation on the effect of freeze-thaw on fracture mode classification in marble subjected to multi-level cyclic loads," Theoretical and Applied Fracture Mechanics, vol. 111, article 102847, 2021.

[7] C. Y. Liu and M. C. He, "Field and laboratory measurements of the depth variations of mechanical properties and weathering degrees of rock structural components in ancient bridge," Journal of Engineering Geology, vol. 2, pp. 222-227, 2007.

[8] M. He, X. Han, C. Liu, and S. Wang, "Investigation on stability of west scriptures printing hall in potala palace, Tibet," Chinese Journal of Rock Mechanics and Engineering, vol. 9, pp. 17841789, 2006.

[9] M. C. He, X. Han, C. Y. Liu, C. H. Sun, and S. R. Wang, "Ground sill stress characteristics and structural deformation analysis of the west scriptures printing hall in the Potala Palace, Tibet," Rock and Soil Mechanics, vol. 2, 2007.

[10] C. Y. Liu and M. C. He, "Study on the deformation failure mechanism and stability of ancient kings tomb: a case of national key cultural relic Gaogouli's Tai kings tomb," Journal of Earth Sciences and Environment, vol. 5, pp. 25-28, 2007.

[11] Z. Li, H. X. Liu, Z. L. Dun, L. Ren, and J. Fang, "Grouting effect on rock fracture using shear and seepage assessment," Construction and Building Materials, vol. 242, p. 118131, 2020.

[12] D. K. Liu, Z. L. Gu, R. X. Liang et al., "Impacts of pore-throat system on fractal characterization of tight sandstones," Geofluids, vol. 2020, 17 pages, 2020.

[13] G. Feng, X. Wang, M. Wang, and Y. Kang, "Experimental investigation of thermal cycling effect on fracture characteristics of granite in a geothermal-energy reservoir," Engineering Fracture Mechanics, vol. 235, article 107180, 2020.

[14] H. Pan, D. Yin, N. Jiang, and Z. Xia, "Crack initiation behaviors of granite specimens containing crossing-double-flaws with different lengths under uniaxial loading," Advances in Civil Engineering, vol. 2020, Article ID 8871335, 13 pages, 2020.

[15] Y. R. Zheng, "Development and application of numerical limit analysis for geological materials," Chinese Journal of Rock Mechanics and Engineering, vol. 31, no. 7, pp. 1297-1316, 2012.

[16] S. R. Wang, X. Wei, and M. C. He, "New method for calculating 3D stability factors of slope and its application in mining,"
Journal of Mining and Safety Engineering, vol. 3, pp. 277-280, 2008.

[17] Y. T. Zhang, X. L. Ding, and B. Lu, "General method for stability evaluation of rock blocks based on numerical simulation," Chinese Journal of Rock Mechanics and Engineering, vol. 36, no. 1, pp. 78-92, 2017.

[18] Z. Li, S. Liu, W. Ren, J. Fang, Q. Zhu, and Z. Dun, "Multiscale laboratory study and numerical analysis of water-weakening effect on shale," Advances in Materials Science and Engineering, vol. 2020, Article ID 5263431, 14 pages, 2020.

[19] X. Wang, C. Liu, S. Chen, L. Chen, K. Li, and N. Liu, "Impact of coal sector's de-capacity policy on coal price," Applied Energy, vol. 265, p. 114802, 2020.

[20] Q. Meng, H. Wang, M. Cai, W. Xu, X. Zhuang, and T. Rabczuk, "Three-dimensional mesoscale computational modeling of soil-rock mixtures with concave particles," Engineering Geology, vol. 277, article 105802, 2020.

[21] C. Zhu, M. C. He, M. Karakus, X. Cui, and Z. Tao, "Investigating toppling failure mechanism of anti-dip layered slope due to excavation by physical modelling," Rock Mechanics and Rock Engineering, vol. 53, no. 11, pp. 5029-5050, 2020.

[22] M. C. He, T. H. Xue, and Y. F. Peng, "A new way of determining mechanical parameters of engineering rock masses," Chinese Journal of Rock Mechanics and Engineering, vol. 2, pp. 225-229, 2001.

[23] G. Qian, X. Gai-Li, and Y. Zhiqiang, "Study of the equivalent identification of rock mass mechanical parameters and numerical simulation of the slope stability," Journal of China University of Mining \& Technology, vol. 44, no. 3, pp. 423-429, 2015.

[24] Z. Li, H. Zhou, D. Hu, and C. Zhang, "Yield criterion for rocklike geomaterials based on strain energy and CMP model," International Journal of Geomechanics, vol. 20, no. 3, article 04020013, 2020. 